\title{
Complications in surgical management of calcaneal fractures with anatomical plates
}

\author{
Asfia Quadri, M. Zeeshan Vasif*
}

Department of Orthopedics, MNR Medical College and Hospital, Sanagreddy, Telangana, India

Received: 14 September 2021

Revised: 19 October 2021

Accepted: 20 October 2021

\author{
*Correspondence: \\ Dr. M. Zeeshan Vasif, \\ E-mail: zeeshan.vasif@gmail.com
}

Copyright: (c) the author(s), publisher and licensee Medip Academy. This is an open-access article distributed under the terms of the Creative Commons Attribution Non-Commercial License, which permits unrestricted non-commercial use, distribution, and reproduction in any medium, provided the original work is properly cited.

\begin{abstract}
Calcaneal fractures, irrespective of their types, are treated non-operatively, one of the reasons being fear of complications. But conservatively managed fractures can result in equally problematic complications. Incidence of subtalar arthritis in such cases is reported to be $16.9 \%$ compared $3.3 \%$ in cases treated surgically. With surgical treatment aimed at achieving anatomical joint reduction, regaining calcaneal height, its length and width, successful attempts at curtailing the long-term complications can be made. This was a prospective study of 20 cases of calcaneal fractures, admitted to MNR Medical College and Hospital, Sangareddy from August 2020 to September 2021 were treated with ORIF with non-locking anatomical calcaneal plates using Fernandez's approach, without use of bone graft. Essex Lopresti and Sander's classification were used. Intra-operative assessment of reduction and articular surface reconstruction was done under fluoroscopic guidance. Regular follow up was done for assessment of fracture union and complications, assessment of late collapse. Among the 20 cases, $73 \%$ were men and $27 \%$ women. On typing the fractures based on Essex-Lopresti classification, intra-articular tongue type constituted $13 \%$ and $87 \%$ were of joint depression. Near normal anatomical reduction was obtained in all cases except in one where it was difficult due to comminution noted during surgery. 2 cases developed superficial skin necrosis at the surgical site, 1 case of deep infection and abscess formation and 3 cases of subtalar arthritis. This study showed that the incidence of long-term complications can probably be minimized by restoring the altered anatomy through surgical means; hence we advocate surgical management and accurate anatomical reduction in cases of displaced and comminuted calcaneal fractures with proper surgical principles.
\end{abstract}

Keywords: Intra-articular calcaneal fractures, Complications, Plate fixation

\section{INTRODUCTION}

Intraarticular fractures account for approximately $75 \%$ of calcaneal fractures and historically have been associated with poor functional outcome. ${ }^{1-3}$ Despite many authors'attempts to define an algorithm for the management of displaced, intra-articular calcaneal fractures, it remains a controversy with strong arguments supporting both conservative and operative managements. ${ }^{4,11,12}$ Recent studies are of varied opinion; some evidences citing no difference between the two and others suggesting operative management to be a better option. ${ }^{13}$ Significant controversy remains over the results of non-operative versus operative treatment. Lack of standardization of results has made it difficult to compare studies that have evaluated outcomes. ${ }^{3}$ Over the past 25 years, however, marked advances in anesthesia, prophylactic antibiotics, CT scanning, and fluoroscopy have allowed surgeons to improve outcomes when operating on fractures, and these techniques have been applied to calcaneal fractures as well. ${ }^{14}$ Overall, operative treatment of acute fractures has become the standard of care for many authors who, critically evaluating their results, have concluded that good outcomes are possible. ${ }^{13}$ Despite these improvements, it is recognized that operative treatment still requires an experienced surgeon and that 
complications may be inevitable. There are only a few studies on this topic making it hard to choose one over the other. We expect this study to be of some use in outlining the outcomes of surgical management of intra articular fractures of the calcaneum. This study would also be of use to test whether; the recent advances in fracture management, better understanding of fracture patterns, better perioperative antibiotic use, rigid fixation and early mobilization has any positive effect on the operative outcomes of calcaneal fracture.

\section{CASE SERIES}

\section{Open reduction and internal fixation with plate and screw}

\section{Lateral approach}

Original lateral approach was described by Kocher. This provided limited access to the calcaneal body and frequently caused scarring of the peroneal tendons and often injury to the sural nerve. Fernandez, in 1984, first described the extensile posterolateral approach. In true lateral position, a tourniquet is applied after exsanguinating the limb.

A lateral incision parallel to the peroneal tendons is taken and extended upwards behind the lateral malleolus. The incision is carried down to the periosteum of the lateral wall. The sural nerve may cross the incision both at its proximal and distal ends, so care is taken to retract it. While performing subperiosteal dissection along the lateral wall, the entire flap with the peroneal tendons and the sural nerve is elevated and held out of the way with a Kirschner wire placed into the lateral malleolus.

The entire lateral wall of the calcaneus is exposed distally to the calcaneocuboid joint. When the exposure is completed, a stepwise reduction is performed.

When a fracture line separates the anterior process from the sustentacular fragment, this part is reduced first to allow better exposure of the relationship between the medial part containing the sustentacular fragment and the lateral tuberosity.

The tuberosity is reduced to the sustentacular fragment and provisionally fixed with Kirschner wires. Now the lateral wall is replaced outwards to allow an anatomical reduction of the posterior facet. Again this provisional fixation is held with Kirschner wires. Intra-operative roentgenograms are taken to assess overall reduction.

Any defect created beneath the reduced posterior facet may be filled with bone graft. The lateral wall is now reduced along the outer edge of the posterior facet and fixation is performed using lag screws and plates. The plate helps to maintain a neutral alignment of the calcaneus. The most anterior screw must be placed into the subchondral bone supporting the calcaneocuboid articular surface and the most posterior screw into the thickened aspect of the calcaneus.

A modification of the lateral approach was described by Seligson and reported by Gould. This incision had a unique undulated plantar limb.

Many authors described problems with the wound healing and sural nerve with various forms of the lateral incision(a) the mean age was 35.93 years (21-43). $40 \%$ of the cases were between the age group 18-30 years; (b) majority of patients were males $14(70 \%)$ and $6(30 \%)$ were females. Male to female ratio was $2.33: 1$; (c) mode of injury was fall from height in $83 \%$ of cases while the rest gave a history of road traffic accident; (d) the side of affection was quite uniform with the right foot being affected in $57 \%$ and the left foot in $43 \%$; (e) the mean pre op heel width was $7.51 \mathrm{~cm}$ which post-operatively reduced to a mean of $6.83 \mathrm{~cm}$; (f) 17 cases (85\%) were of the joint depression type based on Essex Lopresti classification; $(\mathrm{g})$ the average pre-operative Bohler's angle was recorded to be $8.83^{\circ}$ whereas that measured post-operatively averaged at $27^{\circ}$; (h) the crucial angle of Gissane also was seen to be corrected from an average of $158.33^{\circ}$ pre-operatively to $127.83^{\circ}$ post-operatively; (i) the average delay in surgery from the day of injury was 13.1 days; (j) the mean follow up period was 11.86 months; (k) occupational rehabilitation to the patient's pre injury state was achieved in $70 \%$ of cases; (1) our complications and their rates corresponded to other studies, with the incidence of wound necrosis and dehiscence seen in $2(4 \%)$ cases, deep infection in $1(2 \%)$ case and persistent subtalar pain in 3 $(6 \%)$ of the cases.

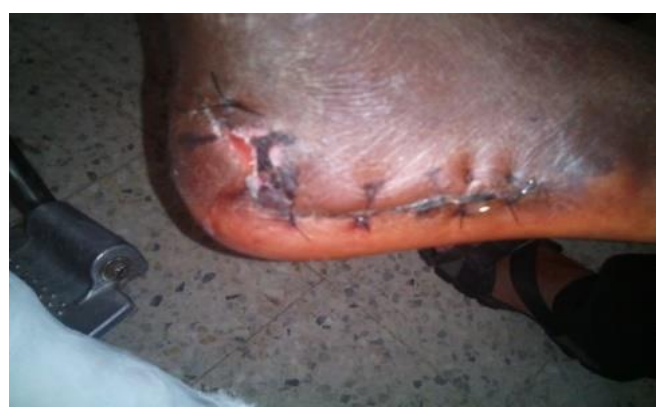

Figure 1: Superficial skin necrosis.

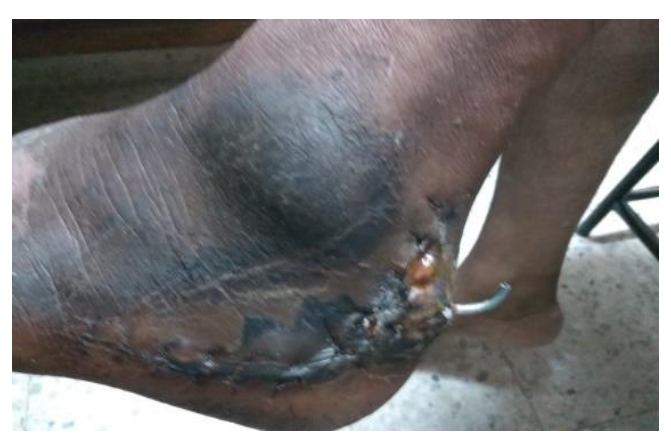

Figure 2: Superficial skin necrosis. 


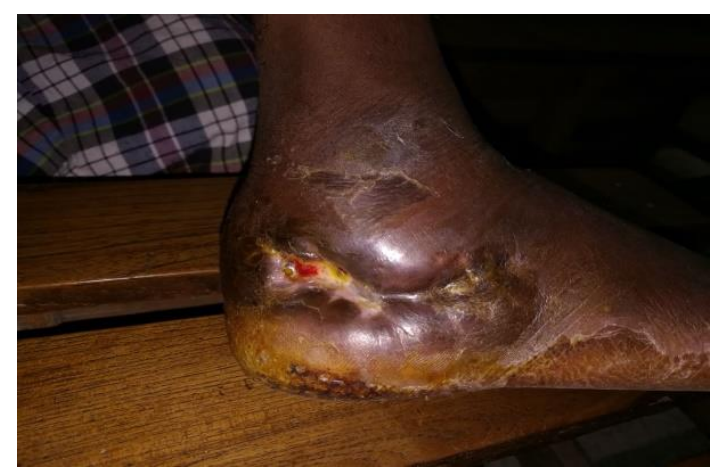

Figure 3: Deep wound dehiscence.

\section{DISCUSSION}

Among the tarsal bones, calcaneum is the most commonly fractured bone. It accounts for $2 \%$ of all fractures and $60-75 \%$ of these fractures are displaced, intra-articular. Calcaneal fractures result in loss of height, varus deformity, heel widening and subtalar joint incongruity. The results for an extra-articular fracture are good with a good prognosis while that for intra-articular fractures are varied. There is controversy with every aspect of management of intra-articular fractures. Though there are different classifications for intra-articular calcaneal fractures, there is no consensus as which is the most practical one among them. Although some studies with more than 100 cases have demonstrated good results after open reduction and internal fixation of intra-articular calcaneal fractures, the best choice of treatment remains controversial because prospective randomized studies have not shown convincingly better results after surgery.

However, in the largest prospective randomized trail done till date, Buckley et al found better results in some subgroups of patients after surgery. Also, it is difficult to compare between different studies as, different measures of outcome are used in different studies and there is no consensus as to which is the most reliable outcome measure. Essex Lopresti and Sander's are commonly used classification system and these show a positive correlation with outcomes but there is no correlation with the choice of treatment.

In the present study, Essex Lopresti classification based on X-rays and Sander's classification based on CT scans have been used.

Cohort studies done previously, have shown similar results with operative and non-operative treatment of displaced and comminuted calcaneal fractures. While some of the more recent studies show no advantage of operative management, others have shown superior results with operative treatment. Earlier operative treatment was considered to be associated with wound complications and sepsis, however, non-operative treatment is also prone to complications like subtalar joint pain, heel varus and peroneal tendon impingement. We believe that like the principles followed for any other weight bearing joints, displaced and comminuted calcaneal fractures should also be treated on the same lines, that is anatomical reduction and rigid internal fixation to allow early movement and get a better functional outcome. Application of these principles to intra-articular calcaneal fractures have been slow because of complex bony and fracture anatomy, tenuous soft tissue envelope and difficulty of achieving anatomic reduction and rigid fixation; improvements that have occurred in surgical techniques, better understanding of the fracture anatomy, better radiographic assistance and improvement in antibiotics have encouraged surgeons to operate more on these fractures without the fear of complications associated with surgical management.

\section{CONCLUSION}

Our study shows that the incidence of calcaneal fractures is about 3 times more in men as compared to women, probably due to their increased involvement in light to heavy outdoor manual work, their risk-taking behaviour. Fall from height emerges to be the most common mode of injury due to the direct axial impact borne by calcaneum, while indirect injuries have a secondary role in their causation.

We conclude that displaced and comminuted calcaneal fractures can be better managed operatively by understanding the fracture anatomy better, by properly timing the surgery, by attempting to minimize the surgical trauma to the soft tissue envelope and by attempting to restore the normal anatomy of the fracture and the joint. It also is important to administer good post-operative wound care to avoid complications of the wound, which should be supplemented with perioperative coverage with a broadspectrum antibiotic. This study has reproduced and thus, reinforces the good results produced by of some of the recent studies which are proponents of surgical management of displaced calcaneal fractures. Hence, we advocated surgical management and accurate anatomical reduction in cases of displaced and comminuted calcaneal fractures with appropriate surgical principles which would aim at accurate reduction of the fracture and the involved joints thus preventing malunion and development of post traumatic arthritis in the long run in turn preventing patients from developing devastating complications that have historically been associated with displaced and comminuted calcaneal fractures.

Funding: No funding sources Conflict of interest: None declared Ethical approval: Not required

\section{REFERENCES}

1. Csizy M, Buckley R, Tough S, Leighton R, Smith J, McCormack R, et al. Displaced intra-articular calcaneal fractures: variables predicting late subtalar fusion. J Orthop Trauma. 2003;17(2):106-12.

2. Sanders R, Fortin P, Pasquale T, Walling A. Operative treatment in 120 displaced intraarticular 
calcaneal fractures. Results using a prognostic computed tomography scan classification. Clin Orthop Relat Res. 1993;(290):87-95.

3. Murphy A. Fractures and Dislocations of the Foot. Campbell's Operative Orthopaedics. 11th ed. Philadelphia, PA: Mosby/Elsevier; 2008: 4833-4848.

4. Randle JA, Kreder HJ, Stephen D, Williams J, Jaglal $\mathrm{S}$, et al. Should calcaneal fractures be treated surgically? A meta-analysis. Clin Orthop Relat Res. 2000;(377):217-27.

5. Rammelt S, Zwipp H. Calcaneus fractures: facts, controversies and recent developments. Injury. 2004;35(5):443-61.

6. Thornes BS, Collins AL, Timlin M, Corrigan J. Outcome of calcaneal fractures treated operatively and non-operatively. the effect of litigation on outcomes. Ir J Med Sci. 2002;171(3):155-7.

7. Dooley P, Buckley R, Tough S, McCormack B, Pate $\mathrm{G}$, Leighton R, et al. Bilateral calcaneal fractures: operative versus nonoperative treatment. Foot Ankle Int. 2004;25(2):47-52.

8. Parmar HV, Triffitt PD, Gregg PJ. Intra-articular fractures of the calcaneum treated operatively or conservatively: a prospective study. J Bone Joint Surg. 1993;75:932-7.

9. Bajammal S, Tornetta P, Sanders D, Bhandari M. Displaced intra-articular calcaneal fractures. J Orthop Trauma. 2005;19(5):360-4.

10. Eastwood DM, Langkamer VG, Atkins RM. Intraarticular fractures of the calcaneum. Part II: open reduction and internal fixation by the extended lateral transcalcaneal approach. J Bone Joint Surg. 1993;75:189-95.

11. Paul M, Peter R, Hoffmeyer P. Fractures of the calcaneum: a review of 70 patients. J Bone Joint Surg. 2004;86:1142-5.

12. Magnan B, Bortolazzi R, Marangon A, Marino M, Dall'Oca C, Bartolozzi P. External fixation for displaced intra-articular fractures of the calcaneum. J Bone Joint Surg Br. 2006;88(11):1474-9.

13. Buckley R, Tough S, McCormack R, Pate G, Leighton R, Petrie D, et al. Operative compared with nonoperative treatment of displaced intra-articular calcaneal fractures: a prospective, randomized, controlled multicenter trial. J Bone Joint Surg Am. 2002;84(10):1733-44.

14. Koval KJ, Sanders R. The radiologic evaluation of calcaneal fractures. Clin Orthop Relat Res. 1993;(290):41-6.

15. Thermann H, Krettek C, Hüfner T, Schratt HE, Albrecht K, Tscherne H. Management of calcaneal fractures in adults. Conservative versus operative treatment. Clin Orthop Relat Res. 1998;(353):107-24.

Cite this article as: Quadri A, Vasif MZ. Complications in surgical management of calcaneal fractures with anatomical plates. Int J Res Orthop 2022;8:94-7. 